The Editorial by Bruce Macfarlane ${ }^{1}$

\title{
Debating higher education
}

In the opening line of the first issue of JPHE in 2019, the editorial team posed the following pertinent and critically reflective question: 'Does the higher education research community really need another research journal?' (The Editorial Team, 2019 , p. 1). In their editorial, they provide a well-argued case for answering this question in the affirmative. The journal's policy statement also makes a good case as to why JPHE is distinctive defining education as 'a moral and political activity' and emphasising the way in which 'the journal is committed to research aimed at the transformation of existing practices and conditions in higher education.' (JPHE, 2022, para. 1). These radical intentions are laudable and will no doubt help to attract like-minded higher education (HE) researchers. A more difficult goal to promote and sustain, however, in the longer term will be the desire to see the journal as a place in which 'debate' plays a central role. The word debate is used no less than five times in the editorial, emphasising the way in which the editors wish to see JPHE as a dynamic forum for discussion.

A number of HE journals make a concerted effort to generate a debate orientation, although such is the dominance of empirical investigation that these types of papers are often assigned to separate sections such as 'points of departure' in Teaching in Higher Education. Other journals have started, and then subsequently closed, such special sections, such 'points for debate' within Higher Education Research \& Development. The reason for this is not so much a lack of desire to stimulate debate on the part of the journal editors but simply a lack of copy. This is because HE researchers are so focused on data collection and analysis as their default method of working and finding a place to publish, that more debate or philosophically-oriented pieces can be challenging when the expectations of some journals are implicitly interpreted in terms of empirical investigation and the attendant need to elaborate a detailed methodology. Argumentation and critique using a qualitative or non-empirical approach can be perceived as academically inferior to quantitative-driven work. This means that those writing debate-oriented papers face a higher chance of being rejected. Philosophically-oriented pieces are also stylistically beyond the comfort zone of many academics more accustomed to reporting their empirical findings. The perception that debate-sections in journals can be perceived to have a lower status, is a further obstacle. As Clinton Golding

\footnotetext{
${ }^{1}$ The corresponding author: Bruce Macfarlane, Faculty of Education and Human Development at the Education University of Hong Kong (profbmac@gmail.com).
} 
asks at the end of his 'points for debate' reflection on why higher education studies is so obsessed with the collection of data, '[s]hould we consider journal articles like this to be research?'

My answer to this question is a definite yes because, in common with Golding, I regard 'research' as constituting many things, not just data collection and analysis. The lengthening cultural shadow of the hard sciences, though, means that research in education and the social sciences is now increasingly seen in narrow, empiricist terms. There is little room or sympathy for philosophical reflection anymore. 'Non-empirical' has become a subtly damning description. There was a time when prestige lay in being a 'searcher' in the sense of seeking 'enlightenment' rather than being a 're-searcher' required to 'grub for facts' (Herrenden-Harker, 1935, p. 112). The philosophical enjoyed a higher status than the empirical. In contemporary journals, however, it is the 're-searcher' rather than the 'searcher' who holds sway and even recognition of this work tends to be framed in performative terms of publishing journal papers in journals with a high impact factor and international ranking. HE research has become a professionalised field of enquiry with a growing global number of academics contributing to its industrialisation. The increasing level of co-authorship is a further indication of the spread of the cultural shadow of the hard sciences. The exponential growth in the number of journal issues published by leading HE journals may be illustrated by reference to Studies in Higher Education. Its first volume in 1976 consisted of just two issues, containing 24 papers produced by a total of 27 authors. By 2014, Studies had expanded to 10 issues comprising 126 papers by 275 contributing authors. In 2020, the journal had expanded even further to 12 issues consisting of 182 papers by 500 listed authors. Despite the rising number of contributors, partly as a function of growing multiple-authorship in addition to the expansion of journal issues, there is limited debate in Studies. Virtually every paper is a standard journal paper and there is little eclecticism in form, such as symposia, debate sections, review essays, articles that reply or respond to a previous one, book reviews or even non-empirical papers. Editorials, except for special issues, rarely appear. Every standard issue consists of one 7,000-word paper after another. It is a highly rated journal in the field but with a repetitious and uninspiring format. Many other journals are much the same in format and style.

If you want to see a how debate and dialogue about HE used to take place in an HE journal, Universities Quarterly provides an example from a by-gone age. Here I am referring to a long-forgotten journal founded in Britain in 1946 that was later re-named Higher Education Quarterly as long ago as 1982. Today it is almost unheard of to see contributions from university leaders to HE journals, but this was quite commonplace in Universities Quarterly (UQ) in the 1950s. Vice Chancellors regularly contributed opinion pieces such as Sir Hector Hetherington of the 
University of Glasgow (in 1953), Charles H. Morris of the University of Leeds (in 1957), Charles Wilson of the University of Leicester (in 1958) and John Fulton of the University of Sussex (in 1964). A lot of debate centred around what was seen as the rapid expansion of the British HE system in the immediate post-war era and the pressures this was bringing to bear on traditional elements of the system, notably the residential model of the university, increasing academic specialisation, the legitimacy of 'new' subjects such, as geography or management studies and the growing spectre of non-completion rates.

Those publishing in UQ during the late 1940s, 50s and 60s also included significant top-line British politicians, such as Rab Butler, Lord Hailsham, when Minister for Science in 1962, Stafford Cripps when he was Chancellor of the Exchequer, and the politician and architect of the post-war welfare state Lord Beveridge. Leading academics and public intellectuals from across the disciplinary spectrum appeared in UQ too. These included the historian Asa Briggs, the mathematician Jacob Bronowski, who later found fame as the presenter of the BBC documentary The Ascent of Man in the early 1970s, the historian Max Beloff, the American sociologist Edward Shils, the social critic R. H. Tawney, and Richard Hoggart, the founding father of cultural studies. Even Anthony Blunt, the art historian who gained notoriety in Britain after being unmasked as a Russian spy in 1979, contributed a paper to UQ in August, 1948.

These various contributions to UQ were, as might be expected, extremely diverse in terms of both topic and what might now be termed academic rigour. However, they were far less diverse, it must be acknowledged, in terms of the representation of diversity during an era when women and minority groups were even more excluded from positions of influence within the university sector than they are today. There were academic shortcomings with UQ, too. Few of the articles published during this period contained many, if indeed any, references to wider literature about HE, although this was perhaps partly because there was little prior research to refer to. Even empirical studies were often presented without a single reference such as Doris Thoday's (1956) investigation into the working patterns of undergraduates in the 1950s. (This was still true of the odd paper published in Studies during the late 1970s (e.g., Cowan, 1978)). Empirical and reflectively analytical contributions were being made to UQ during the 1950s and 60s by what were, in effect, the first generation of HE researchers such as Jean Floud, A.H. Halsey, Martin Trow, Harold Silver, Richard Startup, and Doris Thoday, among others, many of whom went on to make significant contributions to the development of the field.

There was no need for a debate section in UQ because every issue published from the mid-1940s was infused with discussion and a keen focus on the topical. What is genuinely remarkable about UQ, certainly by today's standards, is the 
impressive level of engagement in terms of discussion and debate involving a mix of leading academics across virtually all disciplines, public intellectuals and policy makers. UQ was not an academic journal purely confined, as nearly all are today, to the one-directional presentation of evidence-based investigations by specialist researchers in HE studies but a real forum for discussion and debate about higher education. Editorials, letters to the editor and analyses of government and University Grants Council reports were all regular features. Reports on the Gulbenkian educational discussions during the early 1960s, included topics such as the balance between research and teaching. There were symposia, on medical education for example, and coverage and analysis of other national university systems. Despite the male dominated amateur tradition of the journal a number of papers appeared that might be considered radical or contemporary, even by today's standards, such as the abolition of the lecture (Fletcher \& Knott, 1971), the use of free discussion groups (Johnson, 1952) and the tragic phenomenon of student suicide (Atkinson, 1969). The journal lacked methodological rigour, extensive empirical analysis, academic referencing and had a largely British focus on the policy environment, but there is no doubt that it was able to convey a much stronger sense of the centrality of debate and an interactive intellectual dialogue than any contemporary HE journal that I know of today.

There has never been a time when so much is being published about HE in academic journals. Yet, at the same time, debate about its purposes and practices has never been so weakly represented. There are many important, contemporary HE debates: the de-colonisation of the university, the growing influence of EdTech companies in online learning, the continuing under-representation of women in the professoriate and in senior leadership roles and the equity effects of COVID-19 on all aspects of university life, to name but a few. Yet, contemporary journals focus almost exclusively on publishing stand-alone empirical papers rather than those that seek to engage with philosophical and educational debates in the broader sense of that word about HE as a 'moral and political activity', to borrow a phrase from the founding editorial of this journal. This narrow orientation has grown, as the field of HE studies has professionalised along with its range of contributors, focus and consequent readership. The amateur tradition of the HE researcher has given way to a professional one where contributors are HE research specialists resulting in academic depth rather than intellectual breadth.

There is no magic wand that will change the more insular orientation of contemporary HE journals. The boundaries of the HE research field are now less permeable. Yet, new HE journals, such as JPHE, can help to disturb the status quo by engaging critically with the many tensions, dilemmas, paradoxes, controversies and by enduring questions that face educational researchers. In the process they can make debate and discussion a central focus and encourage reflective, 
philosophically oriented papers as well as empirically-based contributions. HE research badly needs a journal that does something different than the more established ones, that places debate and discussion of the purposes, practices, forms and effects of higher education genuinely at the heart of its mission. It is my sincere hope that JPHE will do its best to take up and sustain this difficult but important challenge.

\section{Acknowledgements}

I am grateful to Kathleen Mahon and Petra Angervall for their feedback on previous drafts of this editorial. 


\section{References}

Atkinson, J. M. (1969). Suicide and the student, Universities Quarterly, 23(2), 213224.

Cowan, J. (1978). Freedom in the selection of course content: a case-study of a course without a syllabus. Studies in Higher Education, 3(2), 139-148.

The Editorial Team (2019) Another higher education journal: Really? Journal of Praxis in Higher Education, 1(1), 1-9.

Fletcher, J., \& Knott, T. (1971). Abolishing the lecture. Universities Quarterly, 26(1), 96-101.

Golding, C. (2013) Must we gather data? A place for the philosophical study of higher education. Higher Education Research \& Development, 32(1), 152155.

Herrenden-Harker, G. F. (1935, April). A plea for the sabbatical year. Universities Review, 7, 109-121.

Johnson, M. L. (1952). Teaching by free discussion groups, Universities Quarterly, 6(3), 290-295.

JPHE. (2022, January $\left.10^{\text {th }}\right)$. About. https://journals.hb.se/jphe/about.

Thoday, D. (1956). How undergraduates work. Universities Quarterly, 11(2), 172181. 